\title{
Muş ili süt sığırcılığı işletmelerinde ırk tercihi ve etkileyen faktörler
}

\section{Breed preference and affecting factors on dairy cattle farms in Muş province}

\author{
Galip BAKIR ${ }^{1}$ (D), Mustafa KİBAR ${ }^{2}$ (D) \\ ${ }^{1}$ Kahramanmaraş Üniversitesi, Ziraat Fakültesi, Zootekni Bölümü, 46000, Kahramanmaraş \\ ${ }^{2}$ Selçuk Üniversitesi, Ziraat Fakültesi, Zootekni Bölümü, 42130, Konya
}

Sorumlu yazar (Corresponding author): G. Bakır, e-posta (e-mail): galipbakir@ hotmail.com Yazar(lar) e-posta (Author e-mail): mustafa.kibar@selcuk.edu.tr

\section{MAKALE BİLGİṠ}

Alınıș tarihi 13 Şubat 2019

Düzeltilme tarihi 07 Mayıs 2019

Kabul tarihi 23 Mayıs 2019

\section{Anahtar Kelimeler:}

Muş ili

Süt sı̆̆ırcılı̆̆ 1

Irk tercihi

Etkili faktörler

\begin{abstract}
ÖZ
Bu araştırma Muş ili ve ilçelerinde süt sığırcılığı işletmelerinde tercih edilen ırkların ve buna etkili faktörlerin değerlendirilmesi amacıyla yapılmıştır. Bu amaçla şansa bağlı olarak seçilen 346 işletmede anket uygulanmış, elde edilen veriler SPSS paket programı kullanılarak çapraz tablolar yapılmıș ve faktör-özellik arasındaki ilişkiler ki-kare analizi ile tespit edilmiștir. İşletmelerde 1 rk tercihinde mevki, hayvan sayısı, işletme tipi ve rrkın etkisi önemli bulunmuştur. Kültür ırkı tercihinde Simental ırkı \%74.9 oranıyla ilk sırada yer alırken, bunu \%15 oranıyla Esmer ırkı izlemiştir. Mevki bazında Hasköy ve Korkut ilçelerindeki işletmeler en fazla kültür ırkını tercih ederken; Merkez, Bulanık ve Varto ilçelerinde ise melez irk tercih edilmektedir. İşletmelerde hayvan sayısı artarken, kültür ırkı tercihi düşmekte ve melez ırk tercihinde artış görülmektedir. Eğitim düzeyi arttıkça kültür ırkı içerisinde Simental tercihi azalırken, esmer tercihi yükselmiştir. Süt tipi işletmelerde kültür ırkı tercih oranı \% 73.2 iken, kombine tipi işletmelerde bu oran \%65.2 olarak tespit edilmiştir. Yerli rrk tercihi sadece kombine tipi işletmelerde yapılmıştır. Hayvancılıktan memnun olan ve işi sürdürmek isteyen işletmelerin ırk tercihi en çok kültür ve melez olurken, kültür ırkı içerisinde de Simental en fazla (\%76.4) tercih edilen irk olmuştur. Genel olarak işletmelerin \%4'ü yerli, \%26.9'u melez ve $\% 69.1$ 'i kültür ırkını tercih etmişlerdir.
\end{abstract}

\section{ARTICLE INFO}

Received 13 February 2019

Received in revised form 07 May 2019

Accepted 23 May 2019

\section{Keywords:}

Muş province

Dairy cattle

Breed preference

Effective factors

\begin{abstract}
This research was conducted to evaluate the race preferred of farmers and factors affect in Mus province and its districts. For this purpose, a face-to-face questionnaire was administered to 346 individuals using the random sampling method. The obtained data were cross-tabulated using the SPSS packet program and the relationship between the factor-features was determined by chi-square analysis. The position, number of animals, type of business and the effect of the breed were found to be significant in farms. In the preference of cultured breeds, Simental was in the first place with $74.9 \%$, followed by Brown Swiss with $15 \%$. On the basis of location, Hasköy and Korkut districts prefer cultured breeds the most, whereas the Central, Bulanik and Varto districts prefer crossbreeds. While the number of animal increases in a farm, the preference for culture breeds decreases and the preference for crossbreed increases. As the level of education increased, the preference of Simental in culture breed decreased while the preference of Brown Swiss increased. In the case of milk type enterprises, the preference rate of cultured breeds was $73.2 \%$, whereas it was found as $65.2 \%$ in combined type enterprises. The native breed is preferred only in combined type enterprises. The preferences of the enterprises who that satisfied with animal husbandry and want to continue their business are mostly cultures and crossbreeds, whereas highest culture breed preference rate was $76.4 \%$. In general, $4 \%$ of the farms preferred local breeds, $26.9 \%$ preferred crossbreeds and $69.1 \%$ preferred culture breeds.
\end{abstract}

\section{Giriş}

Sürdürülebilir bir süt sığırcılığı için hayvanın genetik faktörünün iyi olmasının yanında çevre faktörlerinin de verimi artıracak şekilde düzenlenmesi gereklidir. Genetik faktörlerin içerisinde yüksek süt verimli bir ırk ile çalışmak ilk sırada yer almaktadır. İşletme sahiplerinin ırk tercihine etkili çevre faktörleri bulunmaktadır. Bunlar içerisinde eğitim durumu, işletmecilerin hayvancılık yaptığ 1 süre, işletmenin bulunduğu mevki, işletmede bulunan hayvan sayısı ve işletmecilerin 
hayvancılıktan memnuniyeti gibi faktörler etkili olmaktadır. Bu faktörlerin belirlenmesi, işletmelerde yetiştirilen urkların tercih nedenlerinin bilinmesi ve bölgeye uygunluğunun değerlendirilmesi açısından önemlidir.

$\mathrm{Bu}$ konuda Türkiye'nin farklı bölgelerinde işletmecilerin ırk tercihini belirlemeye yönelik çalışmalar yapılmıştır (Bakır 2002; Tugay 2003; Tugay ve Bakır 2006; Han ve Bakır 2009; Şeker ve ark. 2012). Han ve Bakır (2009) Diyarbakır ili Ergani ilçesinde besi işletmelerinde yapmış olduğu çalışmada melez 1rkların tercih edildiğini ve melez 1rk1 tercih etme oranının eğitim seviyesiyle önemli derecede pozitif ilişkili olduğunu bildirmişlerdir. Aynı araştırıcılar işletmecilerin deneyimleri ile 1rk tercihleri arasında da farklı ilişkiler tespit etmekle birlikte, tüm deneyim gruplarında melez ırk tercihinin ön plana çıtı̆̆ını ve bununla beraber yerli ırklarında tercih edildiğini bildirmişlerdir. Araştırıcılar işletmecilerin yetersiz bakım ve besleme şartlarına, hastalıklara dayanıklı olması ve uzun yürümeye dayanıklı olması sebebiyle yerli 1rkları tercih ettiklerini bildirmişlerdir. Tugay ve Bakır (2006) Giresun yöresindeki yapmış olduğu çalışmada işletmelerde çoğunlukla kültür ve melez ırkların; kültür ırkları içerisinde de Jersey, Esmer ve Siyah Alaca 1rklarının daha çok tercih edildiğini bildirmişlerdir. Aynı araştırıcılar işletmecilerin ırk tercihi yaparken ırkın veriminin yüksek olmasına, bakımının kolay olmasına ve ürünlerinin pazarda yer bulması gibi hususlara dikkat ettiklerini tespit etmişlerdir.

Yukarıdaki çalışmalardan da görüldüğü üzere işletmecilerin ırk tercihini etkileyen birçok faktörün olduğu anlaşılmaktadır. $\mathrm{Bu}$ çalışma ile Muş ili ve ilçelerinde süt sığırcılığı işletmelerinde tercih edilen arkların ve buna etkili faktörlerin değerlendirilmesi amaçlanmıştır.

\section{Materyal ve Yöntem}

Araştırma materyalini, Muş İl Tarım ve Orman Müdürlüğü kayıtlarından elde edilen işletme sayısı dikkate alınarak, Merkez, Bulanık, Malazgirt, Hasköy, Varto ve Korkut olmak üzere 6 ilçede bulunan işletmelerden şansa bağlı olarak seçilen 346 işletmede 2017 yılı Mart ayında yapılan anketlerden elde edilen orijinal veriler oluşturmuştur. Türkvet kaydında hayvan sayısı bir ve iki olarak görülen ancak varlığ s şüpheli olan işletmeler (işletmelerin yaklaşık \%50'si) ankete dâhil edilmemiştir. Anket çalışmalarında örnek hacminin en az \%3 (Yamane 2006) veya \%10'un (Cochran 1977; Arıkan 2000) alınması yeterli olacağı bildirilmiş, ancak örnek hacminin birim sayısı arttıkça ana kitleyi daha iyi temsil etme yeteneğini de yükselteceği bildirilmektedir (Sümbüloğlu ve Sümbüloğlu 2007). Tabakalı örnekleme metodu veya basit tesadüfi örnekleme metodu ile belirlenen örnek sayısı daha az olduğundan bu çalışmada örnek hacmi \%3.3 olarak belirlenmiştir. Elde edilen verilerin SPSS 21.0 paket programı kullanılarak çapraz tabloları yapılmış ve faktör özellik arasındaki ilişkiler Khi-kare analizi ile tespit edilmiştir. (Düzgüneş ve ark. 1983).

\section{Bulgular ve Tartışma}

İşletmelerde 1rk tercihinde mevki, hayvan sayısı, işletme tipi ve ırkın etkisi önemli bulunmuştur. Genel olarak işletmelerin \%4'ü yerli, \%26.9'u melez ve \%69.1'i kültür ırkını tercih etmişlerdir. Kültür 1rkı tercihinde Simental 1rk1 \%74.9 oranıyla ilk sırada yer alırken, bunu \%15 oranıyla Esmer 1rkı izlemiştir (Çizelge 1).

Daş ve ark. (2014) Bingöl ilinde yapmış olduğu çalışma da işletmelerde çoktan aza doğru sırasıyla melez, kültür ve yerli ırkların bulunduğunu tespit etmiştir. Yılmaz ve ark. (2003) Hatay ilinde projesiz süt sığırcılığı işletmelerinde melez irkların oranını \%43.3 olarak yüksek bulmuştur. Van ilinde yapılan araştırmada, işletmelerdeki mevcut sı̆̆ırların \%61.1'ini Sarı Alaca, \%33.5'ini Siyah Alaca ve \%5.4'ünü Esmer rrkın oluşturduğu ve işletmelerin \%8.6'sının Siyah Alaca, \%48.2'sinin Simental, \%26.3'ünün Esmer, \%11.9'unun Simental+Esmer ve \%2.3'ünün Siyah Alaca+Esmer 1rk1 tercih ettikleri bildirilmektedir (Bakır 2002). Muş ilinde yapılan araştırmada işletmelerde yetiştirilen sığır ırklarının \%46.9'unun yerli, \%37.2'sinin melez ve \%15.9'unun ise kültür 1rk1 olduğu ve kültür ırkı sığırların \%70.3'ünün Esmer, \%17.2'sinin Simental ve \%12.5'inin Siyah Alaca rrkından meydana geldiği bildirilmiştir (Şeker ve ark. 2012). Giresun yöresinde yapılan araştırmada ise işletmelerin \%1.6'sının yerli, \%25.2'sinin melez $\% 73.2$ 'sinin kültür 1 rkı sığırları tercih ettiği bildirilmiştir. Yöredeki işletmelerin ark tercihlerini yaparken genel olarak 1rkın veriminin yüksek olması (\%67.3), yetiştirme şartları (\%16.1), bize yetiyor (\%7.8), et verimi yüksek (\%4.6), bakımı kolay (\%1.1), üretilen ürünü değerlendirememe (\%1.3), pazarlaması kolay (\%1.8) gibi kriterleri dikkate aldıkları bildirilmiştir. Yörede yerli irkı tercih eden işletmelerin \%83.3'ü bize yetiyor, kültür 1 rk1 melezini seçen işletmelerin $\% 58.5$ 'i yetiştirme şartlarını ve \%24.5'i bize yetiyor, kültür ırkını tercih

Çizelge 1. İşletmelerde ırk ve kültür ırkı tercihinin mevkiye göre değişimi.

Table 1. Alteration of race and culture race preference as regards region in farms.

\begin{tabular}{|c|c|c|c|c|c|c|c|c|c|c|}
\hline \multirow[b]{2}{*}{ Mevki } & & \multicolumn{3}{|c|}{ Irk tercihi** } & \multirow[b]{2}{*}{ Toplam } & \multicolumn{4}{|c|}{ Kültür ırkı tercihi** } & \multirow[b]{2}{*}{ Toplam } \\
\hline & & Yerli & Kültür & Melez & & Esmer & Simental & Esmer+Simental & Esmer+Simental+Alaca & \\
\hline \multirow{2}{*}{ Merkez } & Adet & 0 & 35 & 19 & 54 & 8 & 39 & 0 & 0 & 47 \\
\hline & & 0.0 & 64.8 & 35.2 & 100.0 & 17.0 & 83.0 & 0.0 & 0.0 & 100.0 \\
\hline \multirow{2}{*}{ Malazgirt } & Adet & 5 & 65 & 12 & 82 & 19 & 46 & 4 & 7 & 76 \\
\hline & & 6.1 & 79.3 & 14.6 & 100.0 & 25.0 & 60.5 & 5.3 & 9.2 & 100.0 \\
\hline \multirow{2}{*}{ Bulanık } & Adet & 9 & 63 & 37 & 109 & 8 & 67 & 15 & 3 & 93 \\
\hline & & 8.3 & 57.8 & 33.9 & 100.0 & 8.6 & 72.0 & 16.1 & 3.2 & 100.0 \\
\hline \multirow{2}{*}{ Hasköy } & Adet & 0 & 19 & 2 & 21 & 0 & 21 & 0 & 0 & 21 \\
\hline & & 0.0 & 90.5 & 9.5 & 100.0 & 0.0 & 100.0 & 0.0 & 0.0 & 100.0 \\
\hline \multirow{2}{*}{ Korkut } & Adet & 0 & 24 & 0 & 24 & 5 & 19 & 0 & 0 & 24 \\
\hline & & 0.0 & 100.0 & 0.0 & 100.0 & 20.8 & 79.2 & 0.0 & 0.0 & 100.0 \\
\hline \multirow{2}{*}{ Varto } & Adet & 0 & 33 & 23 & 56 & 6 & 38 & 0 & 2 & 46 \\
\hline & & 0.0 & 58.9 & 41.1 & 100.0 & 13.0 & 82.6 & 0.0 & 4.3 & 100.0 \\
\hline \multirow{2}{*}{ Toplam } & Adet & 14 & 239 & 93 & 346 & 46 & 230 & 19 & 12 & 307 \\
\hline & & 4.0 & 69.1 & 26.9 & 100.0 & 15.0 & 74.9 & 6.2 & 3.9 & 100.0 \\
\hline
\end{tabular}


edenlerin \%90.9'u verimin yüksek olmasını dikkate almışlardır (Tugay ve Bakır 2006).

Mevki bazında Korkut ilçesindeki işletmecilerin tamamı ve Hasköy ilçesindekilerin \%90.5'i ise kültür rrkını tercih etmişlerdir. En fazla melez 1rkı tercih eden işletmeler Merkez, Bulanık, Varto ilçelerinde bulunmaktadır. Kültür ırkları içinde en fazla tercih edilen irk Simental olurken, en fazla Esmer tercih eden işletmeler Malazgirt ilçesinde tespit edilmiştir (Çizelge 1).

İşletmecilerin hayvancılık yaptığı sürelere göre 1 rk tercihi incelendiğinde Kültür ırkını tercih ettikleri (sırasıyla \%80.4\%67.7-\%59.8-\%71.9) belirlenmiştir (Çizelge 2). 10 y1ldan az hayvancılık yapan işletmeciler $\% 80.4$ oranıyla kültür 1 rkını tercih etmeleri önemli bir gelişme olarak görülmelidir. 21-30 yıl grubundaki işletmelerde Kültür rrkı tercihi \%59.8'e düşerken bu grupta melez tercih oranı \%37.9 olarak bulunmuştur. En fazla yerli 1rk tercihi $31+$ süre grubundaki işletmelerde tespit edilmiştir. Kültür ırkı içerisinde en fazla Simental ırkını 21-30 grubundaki işletmeler tercih ederken, esmer ırkını ise 10 yıldan az deneyimi olan işletmeler tercih etmişlerdir (Çizelge 2).

Hayvan sayısı 9 dan az olan işletmelerin yerli ırkı değil, kültür ırkını tercih ettiği (\%71.6) saptanmıştır. Melez 1rkı en fazla 41 ve üzeri hayvana sahip işletmelerin (\%32.2) tercih ettiği tespit edilmiştir. Esasen hayvan sayısına göre melez $1 \mathrm{rk}$ tercih eden işletmelerin oranı birbirine yakın olup \%21.3 ile
\%32.2 arasında değişmektedir. Genel olarak işletmelerde bulunan hayvan sayısına bağlı olarak 1rk tercihleri de önemli değişiklik göstermiştir (Çizelge 3).

Van ilinde Bakır (2002) tarafindan yapılan araştırmada, işletmelerdeki hayvan sayıları ile işletmecilerin ork tercihleri arasındaki ilişki incelenmiştir. Buna göre, işletmelerdeki hayvan sayısının yetiştiricilerin ırk tercihinde etkili bir faktör olduğu ve 1-5 baş kültür 1rkı sığırı olan işletmelerde, Siyah Alaca 1rkı olan işletmeciler bu ırkın yanında \%46.7 oranında Simental, \%20.7 oranında Esmer, \%15.6 oranında ise Simental+Esmer 1rkını tercih ettiklerini bildirmişlerdir. Simental ırkı olan işletmeler \%54 oranında Simental, \%28.6 oranında Esmer 1rk istemektedirler. Esmer 1rkı olan işletmeler \%55 oranında yine Esmer 1rk1 isterken, bunu \%35 oranıyla Simental 1rkı izlediğini ve 6-10 baş hayvan bulunan gruptaki işletmelerde Siyah Alaca bulunmaması dikkat çekici olduğunu belirtmektedir.

Eğitim durumu urk tercihini önemli etkilemiştir. Okuryazar olmayan işletmeciler kültür ırkını $\% 52$ oranında ve diğerlerine göre en düşük oranda tercih ederken, yine diğerlerine göre yüksek oranda (\%36) melez ırkını tercih etmişlerdir. Kültür ırk1 içerisinde en fazla (\%95.2) tercih edilen kültür 1 rkı olan Simental, okuryazar olmayan işletmelerde tespit edilmiştir. Eğitim düzeyi arttıkça Simental tercihi azalırken, esmer rrk1 tercihi yükselmiştir (Çizelge 4).

Çizelge 2. İşletmelerde ırk ve kültür ırkı tercihinin hayvancıllk süresine göre değişimi.

Table 2. Alteration of race and culture race preference as regards experience in farms.

\begin{tabular}{|c|c|c|c|c|c|c|c|c|c|c|}
\hline \multirow[b]{2}{*}{ Süre (y11) } & & \multicolumn{3}{|c|}{ Irk tercihi** } & \multirow[b]{2}{*}{ Toplam } & \multicolumn{4}{|c|}{ Kültür ırk1 tercihi } & \multirow[b]{2}{*}{ Toplam } \\
\hline & & Yerli & Kültür & Melez & & Esmer & Simental & Esmer+Simental & Esmer+Simental +Alaca & \\
\hline \multirow{2}{*}{$10<$} & Adet & 0 & 74 & 18 & 92 & 14 & 59 & 3 & 4 & 80 \\
\hline & $\%$ & 0.0 & 80.4 & 19.6 & 100.0 & 17.5 & 73.8 & 3.8 & 5.0 & 100.0 \\
\hline \multirow{2}{*}{$11-20$} & Adet & 2 & 67 & 30 & 99 & 14 & 64 & 8 & 2 & 88 \\
\hline & $\%$ & 2.0 & 67.7 & 30.3 & 100.0 & 15.9 & 72.7 & 9.1 & 2.3 & 100.0 \\
\hline \multirow{2}{*}{$21-30$} & Adet & 2 & 52 & 33 & 87 & 9 & 62 & 3 & 2 & 76 \\
\hline & $\%$ & 2.3 & 59.8 & 37.9 & 100.0 & 11.8 & 81.6 & 3.9 & 2.6 & 100.0 \\
\hline \multirow{2}{*}{$31+$} & Adet & 6 & 41 & 10 & 57 & 5 & 38 & 5 & 4 & 52 \\
\hline & $\%$ & 10.5 & 71.9 & 17.5 & 100.0 & 9.6 & 73.1 & 9.6 & 7.7 & 100.0 \\
\hline \multirow{2}{*}{ Toplam } & Adet & 10 & 234 & 91 & 335 & 42 & 223 & 19 & 12 & 296 \\
\hline & $\%$ & 3.0 & 69.9 & 27.2 & 100.0 & 14.2 & 75.3 & 6.4 & 4.1 & 100.0 \\
\hline
\end{tabular}

$* * \mathrm{p}<0.01$.

Çizelge 3. İşletmelerde ırk ve kültür ırkı tercihinin hayvan sayısına göre değişimi.

Table 3. Alteration of race and culture race preference as regards animal number in farms.

\begin{tabular}{|c|c|c|c|c|c|c|c|c|c|c|}
\hline \multirow{2}{*}{\multicolumn{2}{|c|}{ Hayvan sayısı (baş) }} & \multicolumn{3}{|c|}{ Irk tercihi* } & \multirow{2}{*}{ Toplam } & \multicolumn{4}{|c|}{ Kültür ırkı tercihi** } & \multirow{2}{*}{ Toplam } \\
\hline & & Yerli & Kültür & Melez & & Esmer & Simental & Esmer+Simental & Esmer+Simental +Alaca & \\
\hline \multirow{2}{*}{$9<$} & Adet & 0 & 58 & 23 & 81 & 13 & 51 & 7 & 0 & 71 \\
\hline & $\%$ & 0.0 & 71.6 & 28.4 & 100.0 & 18.3 & 71.8 & 9.9 & 0.0 & 100.0 \\
\hline \multirow{2}{*}{$10-20$} & Adet & 7 & 54 & 22 & 83 & 12 & 58 & 4 & 1 & 75 \\
\hline & $\%$ & 8.4 & 65.1 & 26.5 & 100.0 & 16.0 & 77.3 & 5.3 & 1.3 & 100.0 \\
\hline \multirow{2}{*}{$21-40$} & Adet & 1 & 69 & 19 & 89 & 12 & 64 & 5 & 2 & 83 \\
\hline & $\%$ & 1.1 & 77.5 & 21.3 & 100.0 & 14.5 & 77.1 & 6.0 & 2.4 & 100.0 \\
\hline \multirow{2}{*}{$41>$} & Adet & 6 & 53 & 28 & 87 & 9 & 52 & 2 & 9 & 72 \\
\hline & $\%$ & 6.9 & 60.9 & 32.2 & 100.0 & 12.5 & 72.2 & 2.8 & 12.5 & 100.0 \\
\hline \multirow{2}{*}{ Toplam } & Adet & 14 & 234 & 92 & 340 & 46 & 225 & 18 & 12 & 301 \\
\hline & $\%$ & 4.1 & 68.8 & 27.1 & 100.0 & 15.3 & 74.8 & 6.0 & 4.0 & 100.0 \\
\hline
\end{tabular}

${ }^{* \mathrm{p}}<0.05 .{ }^{*} \mathrm{p}<0.01$. 
Elmaz ve ark. (2014) Burdur ilinde süt sığırcılığ işletmelerinde yapmış oldukları çalışmada işletmecilerden ilkokul eğitim seviyesinde olanların oranını \%93.5 olarak bildirmișlerdir. Köseman ve Şeker (2016) Malatya ilinde sığırcıllk işletmelerinde yapmış oldukları çalışmada işletmecilerin eğitim düzeyini üniversite, hayvancılık yaptığ süreyi de 21 y1l ve üzeri olarak bildirmişlerdir. Ergani’de yapılan araştırmada, eğitim düzeyi okuryazar olan ve olmayan işletmeciler yerli 1 rkı tercih ederken (\%48.5), eğitim seviyesi arttıkça melez 1rka doğru bir yöneliş olduğu ve buna ait değerlerin ilkokuldan, lise+'ya kadar (\%52.6, \%75.0 ve \%92.3) artan bir eğilim izlediği belirtilmiştir. Eğitim düzeyi ile rrk seçimi arasındaki ilişki önemli $(\mathrm{P}<0.05)$ bulunmuştur (Han ve Bakır 2009).

İşletme tipi hem ırk ve hem de kültür ırkı tercihini önemli düzeyde etkilemiş̧ir. Süt tipi işletmelerde kültür ırkı tercih oranı \%73.2 iken, kombine tipi işletmelerde bu oran \%65.2 olarak tespit edilmiştir. Yerli rrk tercihi sadece kombine tipi işletmelerde yapılmıştır. Simental 1 rk1 tercih oranı süt tipi işletmelerde \%80.1 iken, kombine tipi işletmelerde \%69.9 olarak bulunmuştur (Çizelge 5).

Muş ilinde Şeker ve ark. (2012) tarafindan yapılan bir araştırmada 1rk seçiminde Muş ilinin karasal iklime sahip olması, yazların sıcak ve kurak, kışların ise oldukça soğuk geçmesinin etkili olduğu bildirilmektedirler. $\mathrm{Bu}$ nedenle yetiştiricilerin kombine verimli olan Esmer ve Simental ırklarının tercihinde hem iklim şartlarına uygun ve daha dayanıklı olan, kültür ırkları içerisinde hastalıklara karşı daha dirençli olan hem de bölgenin sığır besiciliği açısından da önemli bir merkez olması dolayısıyla, besi materyali olarak bu ırkların performanslarından memnun olmalarının etkili olduğu bildirilmektedir. Ayrıca, yetiştiricilerin kültür ırklarını seçimde bilinçli oldukları ve yetiştirme şartlarının uygun olması (\%37.5), veriminin yüksek olması (\%35.4) ve alışkanlıktan dolayı (\%3.1) yetiştiricilerin bu ırkları tercih ettikleri bildirilmektedir.

Hayvancilıktan memnun olan işletmecilerin \%65.8'i kültür ırkını ve \%30.2'si melez 1 'k1 tercih etmişlerdir. Yine bu işletmecilerin kültür ırkı tercihi \%78.9 Simental ve \%12.6 esmer 1rk olmuştur (Çizelge 6). İşi sürdürmek isteyen işletmecilerin ırk tercihi en çok kültür 1rk1 ve melezleri olurken, kültür 1rk1 tercihinde ise en fazla Simental ırkı (\%76.4) olmuştur (Çizelge 7).

İşletmelerde yetiştirilen ırkların işletmecilerin $\quad$ rk tercihlerine etkisi önemli bulunmuştur. Yerli 1rk1 bulunan işletmecilerin sadece \%40.7'si kültür ırkını tercih ederken, bu oran diğer işletmeciler arasında en düşük orana sahiptir. Melez ırkı tercih edenler içerisinde en yüksek oran, yerli 1rk yetiștiren işletmelerde bulunmuştur. Kültür ırkı yetiştiren işletmelerin kültür 1rkı tercihi \%81.8 olması dikkat çekici bulunmuştur. Bu işletmelerin \%18.2' sinin melez ırk tercih etmesi, barınak şartları ve işletmecilerin imkânı ile ilgili olduğu düşünülmektedir. Melez urk yetiştiren işletmelerin tekrar \%30.6 oranında melez 1rk tercih etmeleri bu irktan memnuniyet ve işletme şartlarından kaynaklandığı düşünülmektedir. Yerli rrk1 bulunan işletmecilerin kültür ırkları içerisinde \%57.7 oranında Simental tercih etmeleri anlamlı olup, bu oran diğer 1rk bulunan işletmeler arasında en düşük düzeydedir. Bunun aksine, yerli ırk bulunan işletmelerin esmer ırk tercih oranı ise diğer işletmeler arasında en yüksek düzeyde bulunmuştur (Çizelge 8).

Van ilinde Bakır (2002) tarafından yapılan araştırmada, işletmelerdeki mevcut rrklar ile işletmecilerin ark tercihleri arasındaki ilişki incelenmiştir. Buna göre, ilde Siyah Alaca 1rk1 olan yetiştiricilerin Siyah Alaca tercihi \%9.8 iken, Simental isteyenlerin oran $1 \% 45.9$, Esmer \%20.5, Simental+Esmer isteyenlerin oranı \%16.4 olarak bulunmuştur. Özellikle Siyah

Çizelge 4. İşletmelerde ırk ve kültür ırkı tercihinin eğitim durumuna göre değişimi.

Table 4. Alteration of race and culture race preference as regards educational status in farms.

\begin{tabular}{|c|c|c|c|c|c|c|c|c|c|c|}
\hline \multirow[b]{2}{*}{ Eğitim durumu } & & \multicolumn{3}{|c|}{ Irk tercihi* } & \multirow[b]{2}{*}{ Toplam } & \multicolumn{4}{|c|}{ Kültür ırkı tercihi } & \multirow[b]{2}{*}{ Toplam } \\
\hline & & Yerli & Kültür & Melez & & Esmer & Simental & Esmer+Simental & Esmer+Simental +Alaca & \\
\hline \multirow{2}{*}{ O. yazar değil } & Adet & 3 & 13 & 9 & 25 & 1 & 20 & 0 & 0 & 21 \\
\hline & $\%$ & 12.0 & 52.0 & 36.0 & 100.0 & 4.8 & 95.2 & 0.0 & 0.0 & 100.0 \\
\hline \multirow{2}{*}{ İlkokul } & Adet & 7 & 89 & 44 & 140 & 20 & 94 & 8 & 5 & 127 \\
\hline & $\%$ & 5.0 & 63.6 & 31.4 & 100.0 & 15.7 & 74.0 & 6.3 & 3.9 & 100.0 \\
\hline \multirow{2}{*}{ Ortaokul } & Adet & 3 & 78 & 25 & 106 & 13 & 65 & 7 & 7 & 92 \\
\hline & $\%$ & 2.8 & 73.6 & 23.6 & 100.0 & 14.1 & 70.7 & 7.6 & 7.6 & 100.0 \\
\hline \multirow{2}{*}{ Lise } & Adet & 1 & 57 & 13 & 71 & 12 & 49 & 4 & 0 & 65 \\
\hline & $\%$ & 1.4 & 80.3 & 18.3 & 100.0 & 18.5 & 75.4 & 6.2 & 0.0 & 100.0 \\
\hline \multirow{2}{*}{ Toplam } & Adet & 14 & 237 & 91 & 342 & 46 & 228 & 19 & 12 & 305 \\
\hline & $\%$ & 4.1 & 69.3 & 26.6 & 100.0 & 15.1 & 74.8 & 6.2 & 3.9 & 100.0 \\
\hline
\end{tabular}

Çizelge 5. İşletmelerde ırk ve kültür ırkı tercihinin işletme tipine göre değişimi.

Table 5. Alteration of race and culture race preference as regards farm kind in farms.

\begin{tabular}{|c|c|c|c|c|c|c|c|c|c|c|}
\hline \multirow{2}{*}{ İşletme tipi } & & \multicolumn{3}{|c|}{ Irk tercihi** } & \multirow[b]{2}{*}{ Toplam } & \multicolumn{4}{|c|}{ Kültür ırk1 tercihi** } & \multirow[b]{2}{*}{ Toplam } \\
\hline & & Yerli & Kültür & Melez & & Esmer & Simental & Esmer+Simental & Esmer+Simental +Alaca & \\
\hline \multirow[b]{2}{*}{ Süt } & Adet & 0 & 123 & 45 & 168 & 24 & 121 & 4 & 2 & 151 \\
\hline & $\%$ & 0.0 & 73.2 & 26.8 & 100.0 & 15.9 & 80.1 & 2.6 & 1.3 & 100.0 \\
\hline \multirow{2}{*}{ Kombine } & Adet & 14 & 116 & 48 & 178 & 22 & 109 & 15 & 10 & 156 \\
\hline & $\%$ & 7.9 & 65.2 & 27.0 & 100.0 & 14.1 & 69.9 & 9.6 & 6.4 & 100.0 \\
\hline \multirow{2}{*}{ Toplam } & Adet & 14 & 239 & 93 & 346 & 46 & 230 & 19 & 12 & 307 \\
\hline & $\%$ & 4.0 & 69.1 & 26.9 & 100.0 & 15.0 & 74.9 & 6.2 & 3.9 & 100.0 \\
\hline
\end{tabular}


Çizelge 6. İşletmelerde ırk ve kültür ırkı tercihinin hayvancılıktan memnuniyete göre değişimi.

Table 6. Alteration of race and culture race preference as regards satisfaction of farmers in farms.

\begin{tabular}{|c|c|c|c|c|c|c|c|c|c|c|}
\hline \multirow[b]{2}{*}{ Memnuniyet } & & \multicolumn{3}{|c|}{ Irk tercihi } & \multirow[b]{2}{*}{ Toplam } & \multicolumn{4}{|c|}{ Kültür 1rk1 tercihi } & \multirow[b]{2}{*}{ Toplam } \\
\hline & & Yerli & Kültür & Melez & & Esmer & Simental & Esmer+Simental & Esmer+Simental+ Alaca & \\
\hline \multirow{2}{*}{ Evet } & Adet & 8 & 133 & 61 & 202 & 22 & 138 & 9 & 6 & 175 \\
\hline & $\%$ & 4.0 & 65.8 & 30.2 & 100.0 & 12.6 & 78.9 & 5.1 & 3.4 & 100.0 \\
\hline \multirow{2}{*}{ Hayır } & Adet & 6 & 105 & 30 & 141 & 24 & 90 & 9 & 6 & 129 \\
\hline & $\%$ & 4.3 & 74.5 & 21.3 & 100.0 & 18.6 & 69.8 & 7.0 & 4.7 & 100.0 \\
\hline \multirow[b]{2}{*}{ Toplam } & Adet & 14 & 238 & 91 & 343 & 46 & 228 & 18 & 12 & 304 \\
\hline & $\%$ & 4.1 & 69.4 & 26.5 & 100.0 & 15.1 & 75.0 & 5.9 & 3.9 & 100.0 \\
\hline
\end{tabular}

Çizelge 7. İşletmelerde ırk ve kültür ırkı tercihinin işi sürdürme durumuna göre değişimi.

Table 7. Alteration of race and culture race preference as regards status of go on production in farms.

\begin{tabular}{|c|c|c|c|c|c|c|c|c|c|c|}
\hline \multirow{2}{*}{\multicolumn{2}{|c|}{ İşi sürdürmek }} & \multicolumn{3}{|c|}{ Irk tercihi* ${ }^{*}$} & \multirow{3}{*}{$\begin{array}{c}\text { Toplam } \\
301\end{array}$} & \multicolumn{4}{|c|}{ Kültür ırkı tercihi* } & \multirow{3}{*}{$\begin{array}{r}\text { Toplam } \\
267\end{array}$} \\
\hline & & \multirow{2}{*}{$\begin{array}{c}\text { Yerli } \\
9\end{array}$} & \multirow{2}{*}{$\begin{array}{l}\text { Kültür } \\
209\end{array}$} & \multirow{2}{*}{$\begin{array}{c}\text { Melez } \\
83\end{array}$} & & \multirow{2}{*}{$\begin{array}{c}\text { Esmer } \\
35\end{array}$} & \multirow{2}{*}{$\begin{array}{c}\text { Simental } \\
204\end{array}$} & \multirow{2}{*}{$\begin{array}{c}\text { Esmer+Simental } \\
16\end{array}$} & \multirow{2}{*}{$\frac{\text { Esmer+Simental +Alaca }}{12}$} & \\
\hline & Adet & & & & & & & & & \\
\hline Evet & $\%$ & 3.0 & 69.4 & 27.6 & 100.0 & 13.1 & 76.4 & 6.0 & 4.5 & 100.0 \\
\hline \multirow[b]{2}{*}{ Hayır } & Adet & 5 & 29 & 8 & 42 & 11 & 24 & 2 & 0 & 37 \\
\hline & $\%$ & 11.9 & 69.0 & 19.0 & 100.0 & 29.7 & 64.9 & 5.4 & 0.0 & 100.0 \\
\hline \multirow{2}{*}{ Toplam } & Adet & 14 & 238 & 91 & 343 & 46 & 228 & 18 & 12 & 304 \\
\hline & $\%$ & 4.1 & 69.4 & 26.5 & 100.0 & 15.1 & 75.0 & 5.9 & 3.9 & 100.0 \\
\hline
\end{tabular}

*p<0.05.

Çizelge 8. İşletmelerde ırk ve kültür ırkı tercihinin mevcut ırka göre değişimi.

Table 8. Alteration of race and culture race preference as regards current race in farms.

\begin{tabular}{|c|c|c|c|c|c|c|c|c|c|c|}
\hline \multirow{2}{*}{ Mevcut ırk } & & \multicolumn{3}{|c|}{ Irk tercihi** } & \multirow[b]{2}{*}{ Toplam } & \multicolumn{4}{|c|}{ Kültür ırk1 tercihi* } & \multirow[b]{2}{*}{ Toplam } \\
\hline & & Yerli & Kültür & Melez & & Esmer & Simental & Esmer+Simental & Esmer+Simental +Alaca & \\
\hline \multirow{2}{*}{ Yerli } & Adet & 7 & 11 & 9 & 27 & 7 & 15 & 1 & 3 & 26 \\
\hline & $\%$ & 25.9 & 40.7 & 33.3 & 100.0 & 26.9 & 57.7 & 3.8 & 11.5 & 100.0 \\
\hline \multirow[t]{2}{*}{ Kültür } & Adet & 0 & 45 & 10 & 55 & 7 & 40 & 1 & 0 & 48 \\
\hline & $\%$ & 0.0 & 81.8 & 18.2 & 100.0 & 14.6 & 83.3 & 2.1 & 0.0 & 100.0 \\
\hline \multirow[t]{2}{*}{ Melez } & Adet & 0 & 77 & 34 & 111 & 11 & 81 & 4 & 1 & 97 \\
\hline & $\%$ & 0.0 & 69.4 & 30.6 & 100.0 & 11.3 & 83.5 & 4.1 & 1.0 & 100.0 \\
\hline \multirow[t]{2}{*}{ Yerli+melez } & Adet & 7 & 58 & 26 & 91 & 10 & 53 & 9 & 5 & 77 \\
\hline & $\%$ & 7.7 & 63.7 & 28.6 & 100.0 & 13.0 & 68.8 & 11.7 & 6.5 & 100.0 \\
\hline \multirow[t]{2}{*}{ Kültür+melez } & Adet & 0 & 44 & 13 & 57 & 11 & 37 & 3 & 3 & 54 \\
\hline & $\%$ & 0.0 & 77.2 & 22.8 & 100.0 & 20.4 & 68.5 & 5.6 & 5.6 & 100.0 \\
\hline \multirow{2}{*}{ Toplam } & Adet & 14 & 235 & 92 & 341 & 46 & 226 & 18 & 12 & 302 \\
\hline & $\%$ & 4.1 & 68.9 & 27.0 & 100.0 & 15.2 & 74.8 & 6.0 & 4.0 & 100.0 \\
\hline
\end{tabular}

Alaca ve Siyah Alaca+Esmer irklarına olan tercihin düşük oranlarda bulunması, yörede Siyah Alacaya karşı isteksizlik olduğunu göstermektedir. Ayrıca, ilde bazı işletmelerin hiçbir kültür ırkını istememeleri de dikkat çekicidir. Buna özellikle barınakları yetersiz ve bakım besleme imkânları kıt olan işletmelerde bulunan kültür irklarının kısa sürede elden çıkmasının neden olduğu söylenebilir. İlçede Esmer 1rkı olan işletmelerin \%61.5'inin yine Esmer istemeleri, Esmer 1rkının ilçedeki işletmelere adaptasyonunun iyi olmasına bağlanabilir. Çünkü ilçedeki işletmelerin tamamına yakını barınak şartları kötü ve bakım besleme imkânları yetersiz küçük işletmelerden oluşmaktadır.

Muş ilinde süt sığırcılığı yapan işletmecilerin hayvancılık yapma sebepleri ile tercih ettikleri ırk arasında önemli bir ilişki bulunmuştur $(\mathrm{p}<0.05)$. Buna göre hayvancılı̆̆ baba mesleğ olduğu ve sevdiği için yapan işletmecilerin yerli rk tercih ettiği görülmektedir. Hayvancıllı̆̆ sevdiği için, baba mesleği olduğu için, başka iş olmadığ 1 için ve bunların kombinasyonlarından dolayı bu işi yapan işletmecilerin hepsinin yüksek oranda kültür ırkı tercih ettikleri görülmektedir. Bu durumun kültür ırklarının veriminin yüksek olmasından kaynaklandığ 1 düşünülmektedir. Fakat burada dikkat edilmesi gereken husus, bu mesleği babadan alan işletmecilerin, kültür ırklarına verimlerini ortaya çıkarabilecek çevre şartlarını sunacak bilgi ve ekipmana sahip olmadığından dolayı bir hayvan israfının olduğu söylenebilir. Yine tüm işletmecilerin yüksek oranda Simental rrkı tercih ettiği görülmektedir. Bunun da yetiştiriciler arasındaki iletişimden kaynaklı olduğu düşünülmektedir (Çizelge 9).

Ergani'de yapılan araştırmada, hayvancılıktan memnun olma nedeni olarak önde gelen faktör $(\% 81.5)$ yetiştiricilerin yapacak başka işleri olmamasıdır. Genel eğilimin aksine az oranda da olsa eğitimi lise+ olanlar hayvancılığın karlı olmasını belirtmişlerdir. Deneyimi az ve genç olan yetiştiriciler memnuniyetlerine neden olarak başka işleri olmamasını (\%90.9) belirtirken, deneyimi 14+ yıl olanlar (\%8.6) hayvancılı̆̆ sevdiklerini beyan etmişlerdir. Yetiştiricilerin \%56.3'ünün hayvancılıktan başka işle uğraşmadıkları, ilave iş yapanların da önde gelen uğraş alanı olarak \%32.3 oranıyla süt 
Çizelge 9. İşletmelerde ırk ve kültür ırkı tercihinin hayvancılık yapma nedenine göre değişimi. Table 9. Alteration of race and culture race preference as regards reason of livestock in farms.

\begin{tabular}{|c|c|c|c|c|c|c|c|c|c|c|}
\hline \multirow{2}{*}{\multicolumn{2}{|c|}{ Hayvancılık yapma sebebi }} & \multicolumn{3}{|c|}{ Irk tercihi* } & \multirow{3}{*}{$\begin{array}{c}\text { Toplam } \\
90\end{array}$} & \multicolumn{4}{|c|}{ Kültür 1rkı tercihi } & \multirow{3}{*}{$\frac{\text { Toplam }}{80}$} \\
\hline & & Yerli & Kültür & Melez & & \multirow{2}{*}{$\begin{array}{c}\text { Esmer } \\
8\end{array}$} & \multirow{2}{*}{$\frac{\text { Simental }}{62}$} & \multirow{2}{*}{$\frac{\text { Esmer+Simental }}{7}$} & \multirow{2}{*}{$\begin{array}{c}\text { Esmer+Simental +Alaca } \\
3\end{array}$} & \\
\hline Bahe mesleŏi & Adet & 1 & 67 & 22 & & & & & & \\
\hline Baba mesteg1 & $\%$ & 1.1 & 74.4 & 24.4 & 100.0 & 10.0 & 77.5 & 8.8 & 3.8 & 100.0 \\
\hline \multirow{2}{*}{ Sevmek } & Adet & 1 & 27 & 11 & 39 & 7 & 28 & 0 & 0 & 35 \\
\hline & $\%$ & 2.6 & 69.2 & 28.2 & 100.0 & 20.0 & 80.0 & 0.0 & 0.0 & 100.0 \\
\hline \multirow{2}{*}{ Başka iş yok } & Adet & 7 & 111 & 35 & 153 & 24 & 105 & 5 & 7 & 141 \\
\hline & $\%$ & 4.6 & 72.5 & 22.9 & 100.0 & 17.0 & 74.5 & 3.5 & 5.0 & 100.0 \\
\hline \multirow{2}{*}{ Baba mesleği + sevmek } & Adet & 3 & 7 & 4 & 14 & 2 & 7 & 2 & 1 & 12 \\
\hline & $\%$ & 21.4 & 50.0 & 28.6 & 100.0 & 16.7 & 58.3 & 16.7 & 8.3 & 100.0 \\
\hline \multirow{2}{*}{ Baba mesleğ $\mathrm{i}+\mathrm{iş}$ yok } & Adet & 0 & 16 & 10 & 26 & 4 & 12 & 2 & 1 & 19 \\
\hline & $\%$ & 0.0 & 61.5 & 38.5 & 100.0 & 21.1 & 63.2 & 10.5 & 5.3 & 100.0 \\
\hline \multirow{2}{*}{ Sevmek+iş yok } & Adet & 1 & 6 & 3 & 10 & 1 & 7 & 1 & 0 & 9 \\
\hline & $\%$ & 10.0 & 60.0 & 30.0 & 100.0 & 11.1 & 77.8 & 11.1 & 0.0 & 100.0 \\
\hline \multirow{2}{*}{ Toplam } & Adet & 13 & 234 & 85 & 332 & 46 & 221 & 17 & 12 & 296 \\
\hline & $\%$ & 3.9 & 70.5 & 25.6 & 100.0 & 15.5 & 74.7 & 5.7 & 4.1 & 100.0 \\
\hline
\end{tabular}

Sığırcılığı yaptıkları belirlenmiştir. En fazla ek iş yapmayanlar $\% 84.6$ oranılla eğitimi lise+ olanlar ve daha çok süt sı̆̆ırcılığı ile uğraşanlar ise $\% 58.3$ oranıyla okuryazar olanlardır (Han ve Bakır 2009). Denli ve ark. (2013) Diyarbakır ili sı̆̆ırcılık işletmelerinde yapmış oldukları çalışmada işletmecilerin \%87'sinin hayvancılıktan başka işle uğraşmadığını ve $\% 20$ 'sinin hayvancılıktan memnun olduğunu bildirmiştir. Tugay (2003) yaptığı çalışmada, yetiştiricilikten memnun olma nedenini, \%14 ev ihtiyacı, \%1.7 alışkanlık, \%9.8 geçime katkı, \%73.7 geçim kaynağı, \%0.8 başka işi olmadığı şeklinde bildirmektedir. $\mathrm{Bu}$ araştırma sonuçlarına benzer şekilde, Ildız (1999) Tokat ilindeki işletmelerde sığır varlığının çoğunluğunu Esmer 1rkın (\%55.23) oluşturduğunu kaydetmiştir. Ancak; Bakır (2002), Van ilindeki işletmelerde mevcut kültür ırk1 sığırların, Sarı Alaca (\%61.1), Siyah Alaca (\%33.5) ve Esmer rrklardan (\%5.4) oluştuğunu bildirmiştir.

\section{Sonuç}

Sonuç olarak, yöredeki işletmelerin favori 1rkı Simental olup bunu Esmer rrk izlemektedir. Ancak işletmelerin fiziki şartlarının iyileştirilmesi, bakım ve besleme ile yetiştiricilerin bilgi ve tecrübelerinin artması ile urk tercihlerinde değişme olacağı da göz ardı edilmemelidir. Bu işletmelerin süt yanında besi de yapmak istedikleri tespit edilmiştir. Süt üretimi yapan işletmeler ise Siyah Alacayı tercih etmektedir.

\section{Teșekkür}

Bu çalışmanın yapılmasında emeği geçen Muş İl Tarım ve Orman Müdürlüğünün tüm personeline teşekkür ederiz. Bu çalışmanın tek sayfalık İngilizce genişletilmiş özeti Antalya'da 25-27 Ekim 2019 tarihleri arasında düzenlenen 10. Uluslararası Zootekni Kongresinde yayınlanmıştır.

\section{Kaynaklar}

Arıkan R (2000) Araştırma Teknikleri ve Rapor Yazma. Gazi Kitapevi, Ankara, s. 312.

Bakır G (2002) Van İlindeki Özel Süt Sığırcılığg İşletmelerinde Tercih Edilen Kültür Irkları. Yüzüncü Yıl Üniversitesi Tarım Bilimleri Dergisi 122: 11-20.
Cochran WG (1977) Sampling techniques (3rd Edition). John Wiley\&Sons, New York.

Daş A, İnci H, Karakaya E, Şengül AY (2014) Bingöl ili damızlık sığır yetiştiricileri birliğine bağlı sığırcılık işletmelerinin mevcut durumu. Türk Tarım ve Doğa Bilimleri Dergisi 1(3): 421-429.

Denli M, Sessiz A, Tutkun M (2013) Diyarbakır ili sığırcılık işletmelerinin genel yapısal durumu ve bakım-beslenme teknikleri analizi projesi. Dicle Üniversitesi Ziraat Fak. Zootekni Bölümü.

Düzgüneş O, Kesici T, Gürbüz F (1983). İstatistik Metodları I. Ankara Üniversitesi Ziraat Fakültesi Yay. 229, Ankara.

Elmaz Ö, Saatçi M, Özçelik M, Sipahi C (2014) Burdur ili süt sığırcılı̆̆ı ve özellikleri. Mehmet Akif Ersoy Üniversitesi Veteriner Fakültesi.

Han Y, Bakır G (2009) Özel Besi Sığırcılığı İşletmelerinde Irk Tercihleri ve Besi Uygulamaları. Atatürk Üniv. Ziraat Fak. Dergisi 40(2): 35-41.

Ildız F (1999) Tokat ili merkez ilçesinde ithal sığır yetiştiren tarım işletmelerinin yapısı. Yüksek Lisans Tezi, Ankara Üniversitesi Fen Bilimleri Enstitüsü, Ankara.

Köseman A, Şeker İ (2016) Malatya İlinde Sı̆ğırcılık İşletmelerinin Mevcut Durumu: I. Yapısal Özellikler. F. Ü. Sağ. Bil. Vet. Derg. 30(1): 5-12.

Sümbüloğlu K, Sümbüloğlu V (2007) Biyoistatistik. Hatipoğlu Yayınları, Ankara.

Şeker İ, Tasalı H, Güler H (2012) Muş İlinde Sığır Yetiştiriciliği Yapılan İşletmelerin Yapısal Özellikleri. F.Ü. Sağ. Bil. Vet. Derg. 26(1): 09-16.

Tugay A (2003) Giresun yöresindeki süt sığırcılığı işletmelerinin genel değerlendirilmesi. Yüksek lisans tezi. Yüzüncü Yıl Üniv. Fen Bilimleri Enst, Van.

Tugay A, Bakır G (2006) Giresun Yöresindeki Özel Süt Sığırcıllğı İşletmelerinin Irk Tercihleri ve Barınakların Yapısal Durumu. Atatürk Üniv. Ziraat Fak. Derg. 37(1): 39-47.

Yamane T (2006) Temel örnekleme yöntemleri. Çeviri, Esin, A., Bakır, M.A., Aydın, C, Güzbüzsel, E. Literatür Yayınları: 53, İstanbul.

Yılmaz İ, Dağıstan E, Koç B, Özel R (2003) Hatay ilinde projeli ve projesiz süt sığırcılığ 1 yapan işletmelerin süt sığırcılığı üretim faaliyetlerinin ve faktör verimliliklerinin analizi. Mediterranean Agricultural Sciences 16(2): 169-178. 